\title{
Психолингвистические параметры русских слов и их визуальных коррелятов в языковом сознании тувинско-русских билингвов: опыт экспериментального исследования
}

\author{
Анастасия В. Колмогорова \\ Сибирский федеральный университет, Российская Федерация
}

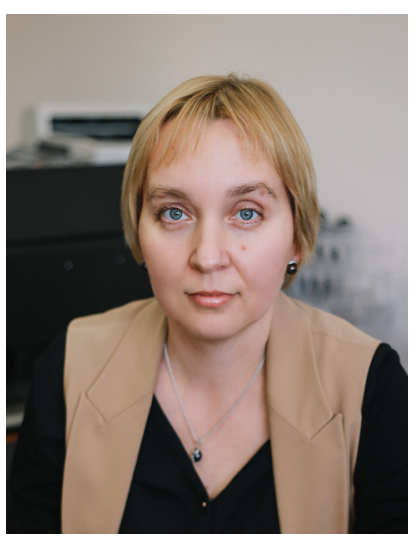

В статье представлены результаты экспериментального исследования субъективных психолингвистических параметров (ПП) русских слов и их визуальных коррелятов в языковом сознании тувинцев-билингвов. Исследование вносит определенный вклад в теорию языковых контактов, би- и транслингвизма, описывая различия когнитивных процессов у монолингвов и билингвов. Получены факты, свидетельствующие об адаптивной природе естественного билингвизма. Показано, что в силу тесного взаимодействия тувинской и русской культур в ситуации двуязычия, слова русского языка в языковом сознании билингвов имеют иные системные связи, нежели у монолингвов.

Одним из способов увидеть эту специфику является экспериментальное исследование. Для его проведения были использованы две серии словесных стимулов и рисунков к ним: 1) список русских существительных, включавший в себя наиболее употребительные слова (е. g. окно, машина, стол), 2) русскоязычные корреляты культурно-значимых слов тувинского языка (е. g. конь, юрта). Для сравнения привлекались данные о ПП существительных серии 1, полученные исследовательской группой Центра языка и мозга НИУ «Высшая школа экономики» на выборке из 100 неврологически здоровых русскоязычных монолингвов. В ходе эксперимента с популяцией из 60 тувинско-русских билингвов без речевых патологий (средний возраст 21,3 года) впервые получены значения ПП «возраст усвоения», «представимость» для 131 русского существительного и значения ПП «сходство образа с рисунком», «субъективная сложность рисунка» - для визуальных коррелятов данных слов.

Получены данные, свидетельствующие о статистической значимости расхождений между значениями всех исследованных параметров вербальных и визуальных стимулов серии 1 в двух группах информантов. При сопоставительном анализе ПП стимулов серии 1 и серии 2 у билингвов обнаружено, что слова, имеющие значимость для тувинской культуры, усваиваются ими в целом позже, чем конкретные существительные серии 1, представляются хуже, а соответствующие рисунки оцениваются как «менее похожие» и более сложные. Полученные наблюдения будут использованы для подготовки речевых упражнений, а также альбомов для нейропсихологической диагностики и проведения курсов речевой терапии тувинскорусских билингвов.

Ключевые слова: тувинский язык; тувинско-русский билингвизм; тувинцы; билингвизм; психолингвистический параметр слова; билингвальное языковое сознание; лингвистический эксперимент; тувинская культура

\section{Для цитирования:}

Колмогорова А. В. Психолингвистические параметры русских слов и их визуальных коррелятов в языковом сознании тувинско-русских билингвов: опыт экспериментального исследования // Новые исследования Тувы. 2021, № 2. C. 197-210. DOI: https://www.doi.org/10.25178/nit.2021.2.16

Колмогорова Анастасия Владимировна - доктор филологических наук, профессор, заведующий кафедрой романских языков и прикладной лингвистики Сибирского федерального университета. Адрес: 660041 Россия, г. Красноярск, пр. Свободный, д. 82а, ауд. 333б. Тел.: +7 (391) 206-57-10. Эл. адрес: nastiakol@mail.ru

KOLMOGOROVA, Anastasia Vladimirovna, Doctor of Philology, Professor and Head, Department of Romance Languages and Applied Linguistics, Siberian Federal University. Postal address: Room 333b, 82a Svobodny Avenue, 660041, Krasnoyarsk, Russia. Tel.: +7 (391) 206-57-10. E-mail: nastiakol@mail.ru 


\title{
Psycholinguistic properties of the Russian words and their visual correlates in the linguistic conscience of Tuvan-Russian bilinguals: an experiment-based study
}

\author{
Anastasia V. Kolmogorova \\ Siberian Federal University, Russian Federation
}

\begin{abstract}
The article summarizes the outcomes of a study of psycholinguistic properties of the Russian words and their visual correlates in linguistic conscience of Tuvan-Russian bilinguals. By describing the different courses that cognitive processes take in monolinguals and bilinguals, the study provides some material for consideration by the theory of language contacts, as well as bi-and translingualism. The materials suggest that natural bilingualism is adaptive in its nature. The article shows that due to close contacts between the two cultures under Tuvan-Russian bilingualism, Russian words have a different set of systemic relations in bilingual's mental lexicon, as compared to Russian monolinguals.

One of the ways to trace this difference is through an experiment-based study. In our experiment, we used two sets of words and corresponding pictures: 1) list of common Russian nouns naming objects (e.g. "window", "car" or "table") and 2) nouns evoking phenomena and objects, which are of particular importance for the Tuvans (e.g. "horse", "yurt"). As reference corpus, we took the results previously obtained by the research group of the Center of Language and Brain (High School of Economics) on the population of 100 neurologically healthy Russian monolinguals. Our population of informants consisted of 60 Tuvan-Russian bilinguals without any speech pathology (average age $=21,3$ ). By the end of the experient, we obtained the values of such psycholinguistic properties as "age of acquisition", "imageability" for 131 Russian words and "image agreement", "image complexity" - for their visual correlates.

Using methods of linguistic experiment, comparative analysis showed that the variation between the values of all four properties for verbal and visual stimuli in the two groups of informants is statistically significant. However, while comparing the properties'values of stimuli from the first set and from the second in bilinguals, we discovered that they master culturally-loaded nouns later than those of set 1, assess them as less imageable and perceive the illustrating pictures as more complex and less similar to their mental image. The evidence obtained evidences will help us in further work on developing speech exercises and albums for neuropsychological diagnostics and speech therapy of Tuvan-Russian bilinguals with aphasia.
\end{abstract}

Keywords: Tuvan language; Tuvan-Russian bilingualism; psycholinguistic properties of a word; bilingual language conscience; linguistic experiment; Tuvan culture

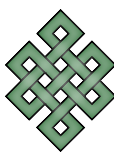

\section{For citation:}

Kolmogorova A. V. Psikholingvisticheskie parametry russkikh slov i ikh vizual'nykh korreliatov v iazykovom soznanii tuvinsko-russkikh bilingvov: opyt eksperimental'nogo issledovaniia [Psycholinguistic properties of the Russian words and their visual correlates in the linguistic conscience of Tuvan-Russian bilinguals: an experiment-based study]. New Research of Tuva, 2021, no. 2, pp. 197-210 (In Russ.). DOI: https://www.doi.org/10.25178/nit.2021.2.16

\section{Введение}

В центре внимания работы - проблема, которая находится в междисциплинарном поле психолингвистики и нейролингвистики, и в которой выявляются место и связи слов русского языка в билингвальном ментальном лексиконе тувинцев.

Подобная работа является частью совместного проекта лаборатории прикладной лингвистики и когнитивных исследований Сибирского федерального университета и отделения восстановления высших психических функций Федерального Сибирского научно-клинического центра Федерального медико-биологического агентства (далее - ФГБУ ФСНКЦ ФМБА России). Проект направлен на изучение специфики речевой и когнитивной деятельности пациентов с афазией. Последняя определяется как «системное нарушение речи, которое возникает при органических поражениях мозга, охватывает разные уровни организации речи, влияет на ее связи с другими психическими процессами и приводит к дезинтеграции всей психической сферы человека, нарушая прежде всего коммуникативную функцию речи» (Цветкова, 1988: 15). На основании наблюдений и экспериментальной работы лингвистов с пациентами ФГБУ ФСНКЦ ФМБА России, имеющими диагноз «афазия», и соответствующими целевыми группами носителей языка без речевых патологий, вносятся коррективы в содержательное 
наполнение программ речевой терапии: производится отбор слов и рисунков, способных максимально эффективно стимулировать импрессивную и экспрессивную речь пациентов.

Одна из таких целевых групп - тувинцы, владеющие тувинским и русским языками, т. е. билингвы.

Билингвальное языковое сознание все чаще привлекает внимание исследователей. Как отмечает Вяч. Вс. Иванов, «раннее усвоение двух или более языков может наложить печать на все последующее развитие ребенка и взрослого» (Иванов, 2004: 124). В экспериментальных работах приводятся доводы в пользу гипотезы о существовании значимых различий в строении и функционировании мозга у билингвов по сравнению с монолингвами. Например, установлено, что у билингвов мозг содержит больше белого и серого вещества, чем у монолингвов (Mechelli et al., 2004; García-Pentón et al., 2014); у них более сильная, чем у монолингвов, нейронная связь между «контролирующими» и «языковыми» зонами мозга (Bialystok, 2009), что способствует большей успешности билингвов при решении когнитивных задач, связанных с переключением внимания, переходом от одних видов деятельности или моторных программ к другим (Kałamała et al., 2018).

Результаты подобных исследований косвенно указывают на необходимость учета специфики системной организации лексикона билингвов при организации речевой терапии. Одной из задач последней является оживление словаря, восстановление способности пациента к актуализации в ментальном лексиконе языковых единиц, соответствующих наблюдаемому референту (функции называния, лексической селекции), и наоборот - установления связи между формой слова и фрагментом действительности, который оно обозначает (узнавание слова). Легкость / сложность такого когнитивного доступа к слову в норме или при патологии речи зависит от ряда взаимосвязанных факторов, которые принято называть психолингвистическими параметрами слова. Например, для монолингвов установленным является факт того, что чем раньше слово было усвоено в детстве (параметр «возраст усвоения»), тем больше вероятность того, что доступ к нему будет проще, чем к другим словам (Morrison, Ellis, Quinlan, 1992). Кроме того, для русских монолингвов уже существуют валидированные в экспериментальной работе с большими популяциями носителей языка библиотеки вербальных стимулов на русском языке (слов) и их визуальных коррелятов (соответствующих изображений).

Однако, исследователи пока не имеют достаточной информации о роли и специфике психолингвистических параметров слов в билингвальном языковом сознании. В частности, не изученными остаются параметры русских слов в языковом сознании тувинцев-билингвов. Таким образом, актуальность исследования обусловлена тем, что в нем предпринимается попытка восполнить данную лакуну.

Полученные нами результаты по четырем субъективным психолингвистическим параметрам впервые вводятся в практику исследований в области тувинско-русского билингвизма и сопоставляются со значениями параметров этих же слов в языковом сознании русских монолингвов, что составляет новизну работы.

Цель статьи - выявить и описать специфику психолингвистических параметров 131 слова на русском языке и соответствующих им рисунков по результатам исследований языкового сознания тувинско-русских билингвов без речевых патологий в сравнении с данными, полученными ранее от русских монолингвов. Психолингвистические параметры слов и визуальных стимулов измерялись в экспериментах со здоровыми носителями языка, поскольку провести аналогичную работу с пациентами, проходящими речевую реабилитацию, невозможно по объективным причинам. Однако в исследовательской практике установлено, что, зная значения параметров у здоровых носителей, можно спрогнозировать их восприятие пациентами с речевыми патологиями, что дает возможность организовать терапию наиболее эффективным способом.

Источниковую базу исследования составили: 1) научная литература по проблемам билингвизма, афазиологии и экспериментальной психолингвистике; 2) результаты экспериментальной работы по измерению значений психолингвистических параметров русских слов, полученные исследовательской группой Центра языка и мозга НИУ "Высшая школа экономики" при работе со 100 неврологически здоровыми русскими монолингвами (Akinina et al., 2015); 3) результаты экспериментальной работы с 60 информантами от 18 до 48 лет, преимущественно жителями г. Кызыла, студентами очного и заочного отделений гуманитарных специальностей Тувинского государственного университета (средний возраст - 21,5 лет, гендерный состав: 51 женщина, 9 мужчин), проведенной исследовательской группой лаборатории прикладной лингвистики и когнитивных исследований Сибирского федерального 
университета под руководством автора данной статьи. Все информанты подтвердили добровольное согласие на участие в эксперименте и дальнейшую анонимизированную публикацию его результатов. Эксперимент с билингвами проводился как в режиме непосредственного контакта с информантами (беседа), так и посредством использования онлайн-платформы.

В соответствии с целью дальнейшее изложение будет построено согласно следующей логике: будет дана краткая характеристика языковой ситуации в Республике Тыва; затем мы представим аналитический обзор исследований архитектуры и функционирования мозга у билингвов по данным афазиологии; дадим краткую характеристику четырех рассматриваемых психолингвистических параметров, опишем дизайн эксперимента и методы обработки полученных данных; также обсудим результаты и остановимся на дискуссионных моментах, а в заключении - подведем основные итоги и наметим перспективы дальнейшего исследования.

\section{Языковая ситуация в Республике Тува: общие замечания}

Становление тувинско-русского билингвизма как социального феномена начинается с момента вхождения Тувы в состав Советского Союза на правах автономной области в 1944 г. За последние несколько десятилетий статус русского языка в республике неоднократно менялся: по Конституции 1996 г. русский язык являлся общефедеральным и государственным, согласно Конституции 2001 г. государственным, в Законе о языках Республики Тыва (2003 г.) зафиксирован его статус как государственного языка и языка межнационального общения (Катунин, 2009).

В силу ряда объективных факторов в постперестроечный период на территории Тувы наблюдалось «снижение функций русского языка и сужение круга владеющих им» (Анайбан, 2011: 20), что, в общем, позволяет говорить о несбалансированной языковой ситуации, при которой уровень владения русским языком достаточно высок в городских поселениях, например, у учащейся молодежи, и может быть минимальным в сельских районах. С другой стороны, сегодня исследователи отмечают, что, поскольку с 2018 г. тувинский язык практически перестал быть языком обучения в системе образования Тувы, он не выдерживает конкуренции с русским языком как доминирующим во многих сферах общения (Арефьев, Бахтикиреева, Синячкин, 2021: 167).

Что касается наших информантов, то следует констатировать, все они на вопрос о родном языке ответили, что это - тувинский язык. При этом 70\% опрошенных общаются на тувинском дома, только $6 \%$ - на работе или учебе. На русском же языке дома разговаривают 9\%, на работе или учебе - 62\%; $12 \%$ используют оба языка дома, а $32 \%$ - на работе или учебе. На вопрос о трудностях в использовании русского языка 56\% опрошенных ответили, что не имеют таковых, 36\% - сталкиваются с ними иногда и 8\% признались в их наличии.

Таким образом даже на нашей выборке заметны признаки неравновесности языковой ситуации, о которой уже писали исследователи: у каждого языка есть своя приоритетная функция: тувинский язык домашнего общения, усваиваемый «стихийно в общении с родными» (Серээдар, 2018: 13), русский - язык социализации. Значительную долю коммуникативного пространства составляет смешанное билингвальное общение.

Этот предварительный вывод подтверждают и субъективные мнения информантов, которым перед проведением эксперимента было предложено написать сочинение «Моя языковая биография». Нижеприведенный отрывок представляет собой субъективную оценку одним из наших информантов функции и роли языков в его жизни:

«Что касается меня, то я считаю, что у меня два родных языка: русский и тувинский. С рождения я выросла в среде, где свободно общаются и на русском и на тувинском языках. Поэтому без труда могу общаться, читать, излагать свои мысли на двух языках. Что касается общения в определенных ситуациях, то русский язык является основным языком коммуникации в моей жизни. Но тувинский язык не менее важен, так как в семье и с друзьями я общаюсь на тувинском языке» (студентка, 18 лет).

Обозначенная характеристика языковой ситуации в республике позволяет предположить, что такие ее признаки, как несбалансированность и неравновесность могут оставить «нейронный след» в когнитивной системе билингвов, в частности под воздействием механизма языковой аттриции (Александрова, 2020). 


\section{Билингвизм и афазия}

Афазия трактуется в нейролингвистике как потеря способности использовать должным образом средства языка в речи (Визель, 2002: 8), дезинтеграция разных звеньев речевой деятельности, обеспечивающих в норме функционирование сложившихся у зрелого носителя языка высокоавтоматизированных типовых моделей слушания - говорения и чтения - письма (Визель, 2009).

В случае индивида, владеющего двумя и более языками, спрогнозировать то, в какой степени процессы дезинтеграции коснутся того или иного языка достаточно трудно. Имеющаяся теоретическая литература противоречива. Тем не менее, авторы выделяют ряд переменных, способных сыграть решающую роль в речевом восстановлении после наступления дефекта (Черниговская, 2017; Goral, Lerman, 2020): возраст усвоения языка (первый по усвоению язык считается более резистентным), степень погруженности в языковую среду (большую эффективность в восстановлении показывает тот язык, в среде которого пациент проходит восстановительное обучение), уровень владения языком в преморбиде ${ }^{1}$ (более оптимистичные прогнозы на восстановление имеет язык, которым пациент владел лучше до наступления дефекта); очаг поражения (существует гипотеза о том, что первый и второй языки по-разному латерализованы (см. напр.: Балонов, Деглин, Черниговская, 2004)); время, прошедшее с момента наступления дефекта до начала терапии (чем оно меньше, тем больше вероятность доступности обоих языков); организация самой речевой терапии (она может иметь коммуникативную направленность, быть фиксированной на восстановлении лексикона или синтаксических паттернов).

Сочетание этих факторов может приводить к нескольким вариантам восстановления языков в процессе речевой терапии: параллельное, в соответствии с теми уровнями владения языками, которые были до диагноза; дифференциальное - один язык восстанавливается лучше, чем другой, хотя до наступления дефекта уровень этого второго языка был выше; антагонистическое - до начала терапии оба языка доступны, но из-за того, что терапевтическая работа ведется только на одном из них, второй исчезает; альтернативное - во время речевой терапии уровень доступности языков периодически меняется; смешанное - происходит смешение элементов и структур двух языков; селективное восстанавливается только один язык; последовательное - сначала восстанавливается один язык, а затем - другой (Lorenzen, Murray, 2008).

Сложность взаимодействия языков с компенсаторными механизмами, обусловленными нейропластичностью, детерминирует необходимость разработки программ восстановительного обучения для пациентов-билингвов на обоих языках. Пока на данный момент в большинстве нейрореабилитационных центров речевая терапия ведется на русском языке по тем же методическим материалам, которые используются при работе с русскими монолингвами. Однако очевидно, что для билингвов вербальные и визуальные стимулы, составляющие основу программы восстановления речи на втором языке, необходимо адаптировать. Исходя из того, что, согласно статистическим данным ФГБУ ФСНКЦ ФМБА России, число тувинско-русских билингвов, поступающих с диагнозом «афазия» в отделение восстановления высших психических функций, с 2017 по 2019 гг. увеличилось с 38 до 68 человек в год, подобная необходимость назрела. Увеличение числа пациентов данной таргет-группы, по-видимому, отражает общую тенденцию в России к росту случаев данного заболевания, социально-экономическими причинами которого являются сидячая работа, низкое качество жизни и увеличение числа стрессогенных факторов, воздействующих на человека.

\section{Психолингвистические параметры слов и дизайн экспериментальной работы}

Первым этапом для разработки упражнений для восстановительного обучения является отбор стимульного материала - слов и изображений, способных инициировать акты называния, лексической селекции, узнавания слова. Критерием для отбора таких стимулов являются психолингвистические параметры слов и соответствующих им изображений.

Психолингвистический параметр (ПП) слова - характеристики словесного стимула, которые устанавливаются путем измерений, проводимых в ходе когнитивных экспериментов (субъективных рейтингов, экспериментальных заданий) с носителями языка, которым слово предъявляется в устной или письменной форме (Paetzold, Specia, 2016).

${ }^{1}$ Преморбид (от лат. prae - ‘впереди’, ‘перед’ и morbus - ‘болезнь') - предболезнь, промежуточная стадия между здоровьем и болезнью. 
Подобные субъективно устанавливаемые параметры влияют на успешность называния объектов/ действий как у здоровых людей, так и у пациентов с афазией (Акинина, Драгой, 2013: 88), поэтому создаются библиотеки вербальных стимулов и их визуальных коррелятов, охарактеризованных по определенным параметрам. Так, например, в русскоязычных библиотеках стимулов «Глагол и действие» и «Существительное и объект» (Akinina et al., 2015; Акинина и др., 2014) представлены значения 7 субъективных ПП. Из них 2 субъективных параметра связаны с самим словом: представимость по пятибалльной шкале информанту предлагается оценить, насколько легко / сложно можно представить себе то, что называется данным словом (1 - легко представить, 5 - сложно); возраст усвоения - информанту предлагается интроспективно оценить, в каком возрасте он выучил данное слово (1-3 года; 4-6; 7-9; 10-12; после 12 лет). Еще 5 параметров связаны с визуальным стимулом, способным актуализировать в ментальном лексиконе индивида данное слово. В нашей работе мы измеряли только 2 из них: сходство образа с рисунком - насколько рисунок отражает то, что представил себе информант, увидев слово; субъективная сложность рисунка - по количеству деталей, линий информанту предлагается оценить по шкале сложность самого изображения (1 простой; 5 - сложный). Хотя исследователи в целом отмечают, что узнавание схематичных и реалистичных изображений представляют собой разные когнитивные процессы (Александрова, 2019), нами использовались достаточно схематичные черно-белые рисунки, поскольку мы частично опирались на экспериментальные данные, полученные другой группой, исследовавшей монолингвов и использовавшей именно такие изображения.

Стимульный материал, который мы отобрали для нашего эксперимента, состоял из следующих серий: серия 1 - 72 русских слова из библиотеки стимулов «Существительное и объект» (Akinina et al., 2015), т. е. каждое десятое слово, например, солнще, варежки, аптека, фотоаппарат и т. д.; серия $2-51$ русскоязычное слово из списка культурно-значимых для тувинцев слов (например, конь, мясо, охота и др. (Цыбенова, 2013)) и 8 слов, выделенных нами самостоятельно путем анализа этнографической литературы: род, река, огонь, обряд, буддизм, оваа, хурээ, чалама. Добавим, что в серию 2 мы намеренно включили 3 лексемы тувинского языка, поскольку хотели посмотреть, будут ли значительно отличаться ПП у культурно-значимых слов на русском языке и на тувинском.

Дальнейший эксперимент существенных отличий не выявил.

Для каждого слова была подобрана картинка: для серии 1 мы взяли визуальные стимулы из той же библиотеки стимулов, что и слова; для серии 2 - подобрали самостоятельно. Все изображения были обработаны в графическом редакторе так, чтобы они имели единый стиль (рис. 1). Разработанный опросник был размещен на платформе Simpoll ${ }^{1}$ и включал в себя 3 блока: так называемую паспортичку (пол, возраст, национальность), социолингвистический блок («Какой язык для вас родной?», «Когда овладели вторым языком?», «На каком языке общаетесь дома?

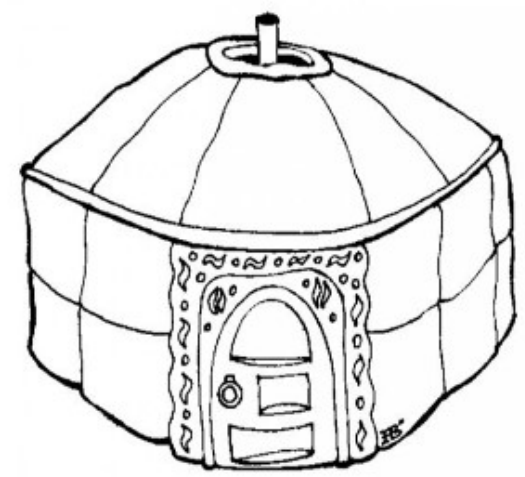

a

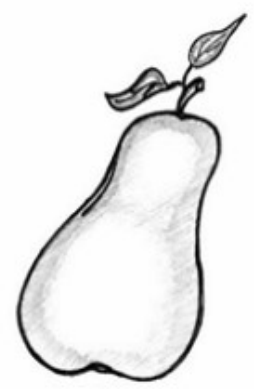

6

Рис. 1. Примеры визуальных коррелятов а) культурно-значимых слов из серии 2-юрта; б) общеупотребительных слов из серии 1 - груша 2 .

Fig. 1 Examples of visual correlates of a) culturally charged words from set 2 (yurt); b) common words from set 1 (pear). на работе/ учебе?», «Испытываете ли трудности при общении на неродном языке?»); по 4 вопроса к каждому слову в соответствии с четырьмя измеряемыми параметрами и еще одна колонка для комментариев.

Обязательным условием было прохождение опросника до конца, время прохождения не ограничивалось. Информанты отвечали на вопросы и выполняли задания онлайн. Перед прохождением опросника с информантами беседовал экспериментатор, настраивая на работу, объясняя задание и условия его выполнения.

${ }^{1}$ https://simpoll.ru/run/survey/873739d9

${ }^{2}$ Использовано с сайта http://stim-database.ru/, см. также: Акинина и др., 2014. 
Нами было сформулировано 2 гипотезы, которые предполагалось проверить по результатам эксперимента, а именно:

- гипотеза 1: между значениями ПП русских слов из серии 1 и их визуальных коррелятов у русских монолингвов и тувинских билингвов будут наблюдаться статистически значимые отличия: у тувинцев значения параметров «возраст усвоения», «представимость», «субъективная сложность рисунка» будут выше, а «сходство образа с рисунком» - ниже;

- гипотеза 2: между значениями ПП слов из серии 1 и слов, обозначающих культурно-значимые для тувинцев реалии и явления из серии 2, а также между значениями ПП для их визуальных коррелятов, у информантов-тувинцев будут наблюдаться отличия: для серии 2 значения параметров «возраст усвоения», «представимость», «субъективная сложность рисунка» будут ниже (раньше усвоили, лучше представляют, несложно), для параметра «сходство образа с рисунком»- выше (больше похоже).

\section{Результаты и обсуждение}

Первый параметр, который мы рассмотрим, - это ПП «возраст усвоения».

В таблице 1 представлены средние значения данного параметра для слов русского языка из библиотеки стимулов «Существительное и объект» (серия 1) по результатам экспериментов с русскими монолингвами и тувинско-русскими билингвами, а также средние значения того же параметра для серии русскоязычных слов, имеющих особую культурную значимость для тувинцев (серия 2). Последние даются без сравнения со значениями у русских монолингвов ввиду отсутствия соответствующих данных. Поскольку для слов серии 1 мы могли провести сравнение в двух выборках, то мы применили статистическую меру известную как двухвыборочный t-критерий Стьюдента. Данный критерий предназначен для оценки статистической значимости отличий значений в двух выборках. Полученное значение p-value оказалось в зоне значимости $-\mathrm{p}<0.05$.

Таблица 1. Средние значения ПП «возраст усвоения» и p-valuе для двух выборок: монолингвы и билингвы. Table 1. Average values of "age of acquisition" psycholinguistic word property and p-value for two data sets: monolinguals and bilinguals.

\begin{tabular}{|c|c|c|}
\hline Русские серия 1 & Тувинцы серия 1 & Тувинцы серия 2 \\
\hline Среднее 1.879 & Среднее 2.511 & Среднее 2.655 \\
\hline \multicolumn{2}{|r|}{$\mathrm{p}<0.05$} & \\
\hline
\end{tabular}

Данные показывают, что гипотеза 1 подтверждается: билингвы, по-видимому, усваивают русские слова позже, нежели монолингвы. Но вторая гипотеза не находит своего подтверждения: культурнозначимые слова из серии 2 усваиваются еще позже, а не раньше, чем «обычные» лексемы из серии 1.

Более детальный анализ выявил «лидеров» и «аутсайдеров» в словах серии 1 у русских монолингвов и билингвов. Так, примерами слов с самым ранним (субъективным) усвоением для монолингвов являются бабушка (101.8 ipm), молоко (57.4 ipm), варежка (4.2 ipm), груша (10.6 ipm), солнце (165.2 ipm), для билингвов - игла (14.3 ipm), ботинки (39.1 ipm), тапочки (9.3 ipm), газета (237.5 ipm). В скобках для каждого слова указаны значения нормализованной частоты по частотному словарю современного русского языка (Ляшевская, Шаров, 2009). Как видим, заметить какую-либо корреляцию с объективной частотностью в языке для данных слов трудно: в каждой из двух групп есть как высокочастотные, так и низкочастотные слова.

Из слов серии 2 самыми «ранними» по субъективным показаниям информантов стали слова мама и сестра, а самыми поздними - артыш, лама и обряд.

Следующий параметр - ПП «представимость».

Данные в таблице 2 представлены аналогичным образом, что и в таблице 1. Вновь применение двухвыборочного t-критерия Стьюдента показывает, что различие в значениях ПП слов серии 1 у монолингвов и билингвов статистически релевантно: первым в целом легче представить себе то, 
что называют данные слова, чем вторым. Таким образом, первая наша гипотеза вновь нашла подтверждение. Но среднее значение анализируемого ПП для слов из серии 2 оказалось у билингвов, вопреки гипотезе, еще выше, чем для серии 1: культурно-значимые слова оказалось представить еще сложнее, чем «обычные».

Таблица 2. Средние значения ПП «представимость» и p-valuе для двух выборок: монолингвы и билингвы. Table 2. Average values of "imageability" psycholinguistic word property and p-value for two data sets: monolinguals and bilinguals.

\begin{tabular}{|c|c|c|}
\hline Русские серия 1 & Тувинцы серия 1 & Тувинцы серия 2 \\
\hline Среднее 1.160 & Среднее 1.360 & Среднее 1.526 \\
\hline & $\mathrm{p}<0.05$ & \\
\hline
\end{tabular}

Среди «хорошо представимых» слов лидерами у монолингвов оказались клубок, груша, нога, перчатка, банан, юла, а у билингвов - клубок, пингвин, тапочки, картина, стакан, шкаф. Как видим, слово клубок повторяется в обоих списках. Обе группы «хорошо представимых» слов относятся к существительным предметной семантики, поэтому легкость, с какой они ассоциируются у информантов с конкретными предметами, вполне объяснима. Однако, удивление вызывает слово пингвин, которое билингвы оценили как очень хорошо представимое слово (минимальное среднее значение - 1.08). Заметно также, что у монолингвов и билингвов фокус «предметных предпочтений» несколько разный.

Среди культурно-значимых слов самыми хорошо представимыми оказались мясо, мама и дедушка, а трудно представимыми - абстрактные существительные религия, свобода и название сакрального объекта оваа (жертвенный курган).

Следующие 2 ПП касаются уже оценки не собственно слова, а изображений, которые его репрезентируют. Надо отметить, что если для ПП слов наша первая гипотеза регулярно подтверждалась, а вторая - нет, то для ПП визуальных стимулов обе гипотезы оказались ошибочными.

Итак, информантам предлагалось оценить рисунки, изображающие денотат слова, по шкале от 1 (совсем непохож) до 5 (очень похож). Мы полагали, что, по сравнению с русскими монолингвами, билингвы будут оценивать визуальные стимулы как менее «похожие» на то, что они представляют, когда произносят или читают слово. Однако результаты показывают обратную тенденцию (табл. 3).

Таблица 3. Средние значения ПП «сходство образа с рисунком» визуального коррелята слова и p-value для двух выборок: монолингвы и билингвы.

Table 3. Average values of "image agreement" psycholinguistic word property and p-value for two data sets: monolinguals and bilinguals.

\begin{tabular}{|l|c|c|}
\hline Русские серия 1 & Тувинцы серия 1 & Тувинцы серия 2 \\
\hline Среднее 4.04 & Среднее 4.39 & Среднее 4.08 \\
\hline & $\mathrm{p}<0.05$ & \\
\hline
\end{tabular}

Значения средних величин данного параметра для слов серии 1 («обычных») ближе к оценке «очень похож», чем у монолингвов. Анализ двух выборок показывает статистическую значимость отличий - p-value < 0.05. А вот рисунки для культурно-значимых слов из серии 2 оценивались билингвами как менее похожие, чем те, что иллюстрировали слова из серии 1.

Аналогичная ситуация и по второму ПП визуальных стимулов - «субъективная сложность рисунка»: для билингвов рисунки для слов серии 1 представлялись более легкими, чем для монолингвов, и это отличие также оказалось статистически значимым. Рисунки же, изображающие культурно-значимые реалии или феномены, называемые словами серии 2, в целом оценивались билингвами как более сложные (табл. 4). 
Таблица 4. Средние значения ПП «субъективная сложность рисунка» визуального коррелята слова и p-valuе для двух выборок: монолингвы и билингвы.

Table 4. Average values of "image complexity" psycholinguistic word property and p-value for two data sets: monolinguals and bilinguals.

\begin{tabular}{|c|c|c|}
\hline Русские серия 1 & Тувинцы серия 1 & Тувинцы серия 2 \\
\hline Среднее 2.77 & Среднее 2.03 & Среднее 2.34 \\
\hline \multicolumn{2}{|c|}{} & \\
\hline
\end{tabular}

На следующем этапе обработки данных мы сравнили корреляции значений ПП для слов серии 1 по показаниям языкового сознания русских монолингвов и тувинско-русских билингвов.

В исследовательской литературе по нейролингвистике отмечается, что параметры «возраст усвоения» и «представимость» (или образность) тесно взаимосвязаны (Ахутина, 2014; Власова, 2016: 187). Действительно, корреляционный анализ по Спирмену показал наличие средней корреляции между данными ПП у русских монолингвов, однако, у билингвов эта корреляция оказалась слабой (табл. 5).

Таблица 5. Значения коэффициента ранговой корреляции Спирмена для пар ПП слов серии 1 и их визуальных коррелятов в двух выборках: русских монолингвов и тувинско-русских билингвов.

Table 5. Spearman's rank correlation coefficient values for psycholinguistic properties of words from set 1 and their visual correlates in two data sets: monolinguals and bilinguals.

\begin{tabular}{|c|c|c|}
\hline Коррелирующие ПП & Русские монолингвы & Тувинско-русские билингвы \\
\hline $\begin{array}{l}\text { «возраст усвоения слова» / } \\
\text { «представимость слова» }\end{array}$ & $\begin{array}{c}0.362 \text { (средняя корреляция) } \\
0.002 \text { - вероятность, что образцы не } \\
\text { коррелированы }\end{array}$ & $\begin{array}{c}0.15 \text { (слабая корреляция) } \\
0.208 \text { - вероятность, что } \\
\text { образцы не коррелированы }\end{array}$ \\
\hline $\begin{array}{l}\text { «возраст усвоения слова» / } \\
\text { «сходство образа с рисунком» }\end{array}$ & $\begin{array}{c}0.215 \text { (средняя корреляция) } \\
0.070 \text { - вероятность, что образцы не } \\
\text { коррелированы }\end{array}$ & $\begin{array}{c}0.038 \text { (нет корреляции) } \\
0.754 \text { - вероятность, что } \\
\text { образцы не коррелированы }\end{array}$ \\
\hline $\begin{array}{c}\text { «возраст усвоения слова» / } \\
\text { «субъективная сложность рисунка» }\end{array}$ & $\begin{array}{c}0.038 \text { (нет корреляции) } \\
0.754-\text { вероятность, что образцы не } \\
\text { коррелированы }\end{array}$ & $\begin{array}{c}0.108 \text { (слабая корреляция) } \\
0.366 \text { - вероятность, что } \\
\text { образцы не коррелированы }\end{array}$ \\
\hline $\begin{array}{c}\text { «представимость слова» / «сходство } \\
\text { образа с рисунком» }\end{array}$ & $\begin{array}{c}0.406 \text { (сильная корреляция) } \\
0.000 \text { - вероятность, что образцы не } \\
\text { коррелированы }\end{array}$ & $\begin{array}{c}0.022 \text { (нет корреляции) } \\
0.855 \text { - вероятность, что } \\
\text { образцы не коррелированы }\end{array}$ \\
\hline
\end{tabular}

Прим.: в круглых скобках указаны оценки силы корреляционной связи, согласно шкале Чеддока (для отрицательной и положительной связи): слабая, средняя и сильная; значения вероятности существования корреляции даются ниже в форме числовых значений в континууме «0 - образцы не коррелируют; 1 образцы коррелируют».

Между ПП «возраст усвоения» и «сходство образа с рисунком», а также «представимость» / «сходство образа с рисунком» у монолингвов наблюдаются средняя и сильная корреляции соответственно. У билингвов ни в одном из этих случаев корреляции нет. По-видимому, ПП «возраст усвоения слова» / «субъективная сложность рисунка» в данной выборке не коррелируют друг с другом.

Таким образом, получается, что у русских монолингвов наблюдаются следующие тенденции: чем раньше слово усвоено, тем лучше представляется его денотат, тем больше похож рисунок на то, что представляет себе информант; чем лучше себе представляет денотат слова информант, тем выше он оценивает сходство этого образа с предъявленным рисунком, его изображающим. 
У тувинско-русских билингвов замечены только две очень слабые тенденции: если слово усвоено рано, то есть некоторая вероятность того, что его денотат лучше представляется информантом, а рисунок, его изображающий, окажется субъективно менее сложным. Есть основания полагать, что ПП «возраст усвоения слова» не является в той же степени определяющим для устройства ментального лексикона билингвов, в какой он является таковым для монолингвов.

Иными словами, наша первая гипотеза в ходе исследования частично подтвердилась: различия между значениями ПП общеупотребительных слов конкретной семантики у русских монолингвов и тувинских билингвов статистически значимы, но 1) для билингвов образ, вызванный словом, гораздо более похож на предъявляемый рисунок, чем для монолингвов; 2) билингвам рисунок, изображающий денотат слова, представляется гораздо более простым, чем монолингвам.

Однако вторая гипотеза не получила подтверждения: у тувинско-русских билингвов ПП культурнозначимых слов и «обычных» отличаются, но это отличие незначимо статистически и идет вразрез с изначальным предположением - культурно-значимые слова усваиваются позже, представляются хуже, их денотаты меньше похожи на рисунок, который оценивается как сложный или очень сложный.

Для нас оказалось неожиданным, что даже такие слова, денотат которых является необычным для повседневной жизни жителей Тувы, (например, пингвин, кенгуру, осьминог, скорпион, ракета и др.), оцениваются информантами как, в целом, усвоенные раньше, лучше представимые, чем культурнозначимые слова (например, конь, аржаан, тайга, чалама, очаг, небо, восток), а изображения культурнозначимых слов оцениваются как менее похожие и более сложные (табл. 6).

Таблица 6. Сравнительный анализ средних значений четырех ПП в трех группах слов: называющих обычные повседневные, необычные и культурно-значимые объекты и реалии.

Table 6. Comparison of the average values of four psycholinguistic properties in three groups of words: those naming familiar, unfamiliar and culturally charged objects and facts of life.

\begin{tabular}{|c|c|c|c|}
\hline $\begin{array}{c}\text { ПП/ группы слов по типам } \\
\text { денотатов }\end{array}$ & Обычные & Необычные & Культурно-значимые \\
\hline & \multicolumn{3}{|c|}{ среднее значение (стандартное отклонение) } \\
\hline Возраст усвоения & 2.32 & 2.66 & 2.65 \\
\hline $\begin{array}{c}\text { Представимость } \\
1-\text { легко / } 5 \text { - сложно }\end{array}$ & 1.32 & 1.35 & 1.52 \\
\hline $\begin{array}{c}\text { Сходство образа с рисунком } \\
1 \text { - непохож, } 5 \text { - очень похож }\end{array}$ & $4.32(0.778)$ & $4.49(0,191)$ & $4.08(0.628)$ \\
\hline $\begin{array}{c}\text { Сложность рисунка } \\
1 \text { - простой, } 5 \text { - сложный }\end{array}$ & 1.92 & 2.09 & 2.34 \\
\hline
\end{tabular}

Полученные данные указывают на такую особенность: хотя среднее значение оценки сходства для «обычных» объектов (кастрюля, чашка и т. д.) выше, чем для «культурно-значимых», среднее квадратичное отклонение тоже выше. Последнее указывает на то, что оценка рисунков «культурнозначимых» объектов как «непохожих» на то, что представляют себе информанты, более согласована, чем оценка «обычных» как «похожих». Можно предположить, что представления о последних более индивидуальны, поскольку связаны с конкретными предметами обихода в каждой отдельной семье, а о «культурно значимых» - хотя и более детальны (отсюда неудовлетворенность рисунком), но имеют некий общий базис у всех представителей сообщества.

\section{Заключение}

В заключение отметим некоторые основные практические выводы, важные для нашей дальнейшей клинической работы с тувинско-русскими билингвами с диагнозом «афазия».

Для их речевой реабилитации и тестирования речевой способности, по-видимому, следует избегать культурно-значимых существительных, а сосредоточиться на словах конкретной семантики, 
называющих объекты повседневной жизни, членов семьи. В отличие от монолингвов, возраст усвоения существительного для билингвального языкового сознания наших информантов не является релевантным ПП, а хорошая представимость слова, по всей видимости, никак не связана с редкостью / частотой встречаемости объектов номинации в непосредственном когнитивном опыте, поэтому выборка слов для тестирования / реабилитации мало зависит от принципа «близкий - далекий» объект номинации.

Очевидно, что отличия между значениями ПП у монолингвов и билингвов статистически значимы, поэтому для получения валидной тестовой батареи необходима дальнейшая проверка обширного корпуса слов на представительной и сбалансированной выборке информантов-билингвов.

Возможно, большую роль для успешности называния будут играть объективные параметры (объективная частотность, длина слова в слогах и фонемах), а не субъективные.

В дальнейшем полученные наблюдения станут основой для разработки речевых упражнений, предназначенных для пациентов из Республики Тыва с диагнозом «афазия», проходящих курс восстановительного обучения в ФГБУ ФСНКЦ ФМБА России.

С точки зрения теоретического осмысления интересным представляется выявленная важность различения трех типов денотатов слов: необычных, обычных и культурно-значимых. У «необычных» слов в языковом сознании тувинцев-билингвов преобладает номинативная функция - слово, обозначая объект, который в личном опыте билингва не встречается, ассоциируется у него с некоторым денотативным минимумом, наличие которого обеспечивает конвенциональное взаимопонимание с другими носителями русского языка. Когнитивная структура, актуализируемая «обычными» словами, формируется на основе стандартного опыта взаимодействия со словом (типовые контексты повседневной речи) и следов взаимодействия с номинируемыми объектами в индивидуальном опыте, который может иметь некоторую особенную конфигурацию. По этой причине номинативная функция слова, находясь в равновесных отношениях с сигнификативной, может базироваться на представлениях о денотативной отнесенности слова, почерпнутых в индивидуальном обыденном опыте (например, денотативный образ чайника - это тот чайник, который у нас дома). Отсюда несогласованность в оценках информантов.

У «культурно-значимых» русских слов в языковом сознании тувинцев-билингвов очевидно доминирует сигнификативная функция, причем значение слова формируется из результатов когнитивного и аффективного опыта, полученного в тувинской культуре, хотя сам знак принадлежит иному языку. Возможно, именно этот культурный и когнитивный трансфер и обусловливает субъективное восприятие таких слов как плохо представимых, поздно усвоенных, для которых предложенный рисунок не подходит, а также является слишком сложным.

Нерелевантность же параметра «возраст усвоения», как представляется, может быть связана с уже упоминавшимися механизмами языковой аттриции (ослабление или полное стирание того или иного языка), действие которых может приводить к потере освоенных слов и их повторному освоению. Факт лучшей «представимости» русских слов конкретной семантики у билингвов, по сравнению с монолингвами, можно частично связать с большей выраженностью у первых процессов схематизации образов, поскольку каждый образ у владеющих несколькими языками связан не с одним словом, а с двумя словами из разных языков.

\section{Благодарности}

Автор выражает свою искреннюю благодарность коллективу отделения восстановления высших психических функций ФГБУ ФСНКЦ ФМБА России и лично заведующему отделением О. Н. Никольской, а также доценту кафедры романских языков и прикладной лингвистики СФУ М. К. Мжельских, студентам О. А. Катцыной и А. А. Зоновой за помощь, оказанную на различных этапах исследования.

\section{СПИСОК ЛИТЕРАТУРЫ}

Акинина, Ю. С., Драгой, О. В. (2013) Оценка эффективности терапии называния при афазии как контролируемый лингвистический эксперимент // Вестник Московского университета. Серия 9: Филология. № 3. С. 86-100.

Акинина, Ю. С., Искра, Е. В., Иванова, М. В., Грабовская, М. В., Исаев, Ю. Д., Коркина, И. Д., Малютина, С. А., Сергеева, Н. Ю. (2014) Библиотека стимулов «Существительное и объект»: нормирование психолингвистических 
параметров // Тезисы докладов Шестой международной конференции по когнитивной науке. Калининград, 23-27 июня 2014 г. / ред. А. А. Кибрик и др. Калининград : б. и. 752 с. С. 112-114.

Александрова, Н. Ш. (2019) Зрительные агнозии и двойственность зрительного опознания // Нелинейная динамика в когнитивных исследованиях - 2019: материалы научной конференции / отв. ред. В. А. Антонец, С. Б. Парин, В. Г. Яхно. Нижний Новгород : ИПФ РАН. 234 с. С. 22-26.

Александрова, Н. Ш. (2020) Билингвизм и другие проявления функционирования языковой системы в свете пластичности мозга // Филологические науки. Научные доклады высшей школы. № 6-2. C. 170-176. DOI: https:// www.doi.org/10.20339/PhS.6-20.170

Анайбан, 3. В. (2011) Межэтническая ситуация и этнополитические процессы в постсоветской Туве / Исследования по прикладной и неотложной этнологии. М. : ИЭА РАН. Вып. 227. 25 с.

Арефьев, А. Л., Бахтикиреева, У. М., Синячкин, В. П. (2021) Проблемы билингвизма в системе школьного языкового образования Республики Тыва // Новые исследования Тувы. № 1. С. 255-272. DOI: https://www.doi. org/10.25178/nit.2021.1.14

Ахутина, Т. В. (2014) Связь семантической сложности, времени приобретения и частотности слова // Нейролингвистический анализ лексики, семантики и прагматики. М. : Языки славянской культуры. 424 с. С. $186-189$.

Балонов, Л. Я., Деглин, В. Л., Черниговская, Т. В. (2004) Функциональная асимметрия мозга в организации речевой деятельности // Хрестоматия по нейропсихологии / отв. ред. Е. Д. Хомская. М. : Институт общегуманитарных исследований ; Московский психолого-социальный институт. 896 с. С. 527-541.

Визель, Т. Г. (2002) Нейролингвистический анализ атипичных форм афазий (системный интегративный подход) : автореф. дисс.... д-ра псих. н. М. 49 с.

Визель, Т. Г. (2009) К вопросу о природе афазии // Дефектология. № 6. С. 65-70.

Власова, Р. (2016) Нормативная база рисунков «Предмет и действие» // Российский журнал когнитивной науки. Т. 3 (1-2). С. 34-54.

Иванов, Вяч. Вс. (2004) Лингвистика третьего тысячелетия: Вопросы к будущему. М. : Языки славянской культуры. 208 с

Катунин, Д. А. (2009) Языковое законодательство в республиках Сибири // Язык и культура. № 4 (8). С. 13 -24.

Ляшевская, О. Н., Шаров, С. А. (2009) Частотный словарь современного русского языка (на материалах Национального корпуса русского языка). М. : Азбуковник. 1112 с.

Серээдар, Н. Ч. (2018) Тувинский язык как средство общения тувинцев: проблемы и перспективы // Новые исследования Тувы. № 1. С. 4-19. DOI: https://www.doi.org/10.25178/nit.2018.1.1

Черниговская, Т. В. (2017) Латерализация языков у билингва // Черниговская Т. В. Чеширская улыбка кота Шредингера : язык и сознание. М. : Издательский Дом ЯСК ; Языки славянской культуры. 448 с. С. $251-261$.

Цветкова, Л. С. (1988) Афазия и восстановительное обучение. М. : Просвещение. 207 с.

Цыбенова, Ч. С. (2013) Ассоциативный эксперимент в контексте исследования языковой ситуации: на примере Республики Тыва // Вопросы психолингвистики. Вып. 17. С. 180-193.

Akinina, Y., Malyutina, S., Ivanova, M., Iskra, E., Mannova, E., Dragoy, O. (2015) Russian normative data for 375 action pictures and verbs // Behavior Research Methods. Vol. 47 (3). P. 691-707.

Bialystok, E. (2009) Bilingualism: The good, the bad, and the indifferent // Bilingualism: Language and Cognition. Vol. 12(1). P. 3-11. DOI: https://doi.org/10.1017/S1366728908003477

García-Pentón, L., Pérez Fernández, A., Iturria-Medina, Y., Gillon-Dowens, M., Carreiras, M. (2014) Anatomical connectivity changes in the bilingual brain // NeuroImage. Vol. 84. P. 495-504. DOI: https://doi.org/10.1016/j. neuroimage.2013.08.064

Goral, M., Lerman, A. (2020) Variables and Mechanisms Affecting Response to Language Treatment in Multilingual People with Aphasia // Behavioral Sciences. Vol. 10. P. 144-157. DOI: https://doi.org/10.3390/bs10090144

Kałamała, P., Drozd'zowicz, A., Szewczyk, J., Marzecov'a, A., Wodniecka, Z. (2018) Task strategy may contribute to performance differences between monolinguals and bilinguals in cognitive control tasks: ERP evidence // Journal of Neurolinguistics. Vol. 46. P. 78-92. DOI: https://doi.org/10.1017/S1366728913000564

Lorenzen, B., Murray, L. (2008) Bilingual Aphasia: A Theoretical and Clinical Review // American Journal of SpeechLanguage Pathology. Vol. 17. P. 299-317. DOI: https://doi.org/10.1044/1058-0360(2008/026) 
Mechelli, J. T. Crinion, U., Noppeney, J., O’Doherty, J., Ashburner, R. S. Frackowiak, Price, C. J. (2004) Structural plasticity in the bilingual brain: Proficiency in a second language and age at acquisition affect grey-matter density // Nature. Vol. 431 (7010). P. 757. DOI: https://doi.org/10.1038/431757a

Morrison, C. M., Ellis, A. W., Quinlan, P. T. (1992) Age of acquisition, not word frequency affects object naming, not object naming, not object recognition// Memory \& Cognition. Vol.20.P.705-714.DOI: https://doi.org/10.3758/BF03202720

Paetzold, G., Specia, L. (2016) Inferring Psycholinguistic Properties of Words // Proceedings of NAACL-HLT 2016, San Diego, California, June 12-17. P. 435-440. DOI: https://doi.org/10.18653/v1/N16-1050

Дата поступления: 11.04.2021 2.

\section{REFERENCES}

Akinina, Yu. and Dragoy, O. (2013) Otsenka effektivnosti terapii nazyvania pri afazii kak kontroliruemyy lingvisticheskii eksperiment [Assessment of therapy effectiveness in case of aphasia as a controlled linguistic experiment]. Bulletin of Moscow State University, series 9, Filologiya, no. 3, pp. 86 -100. (In Russ.).

Akinina, Yu., Iskra, E., Ivanova, M., Grabovskaya, M., Isaev, Yu., Korkina, I., Malyutina, S. and Sergeeva, N. (2014) Biblioteka stimulov «Sushchestvitel'noe i ob'ekt»: normirovanie psikholingvisticheskikh parametrov [The "Noun and object” stimuli set: normalizing psycholinguistic properties]. In: Tezisy dokladov Shestoy mezhdunarodnoy konferentsii po kognitivnoy nauke [Proceedings of the Sixth International Conference on Cognitive Science], Kaliningrad, 23-27 June 2014 / ed. by A. A. Kibrik et al. Kaliningrad, s. n. 752 p. Pp. 112-114. (In Russ.).

Aleksandrova, N. Sh. (2019) Zritel'nye agnozii i dvoystvennost' zritel'nogo opoznaniya [Visual agnosies and doubleness of visual recognition]. In: Nelineynaia dinamika $v$ kognitivnykh issledovaniakh - 2019 [Non-linear dynamics in cognitive studies - 2019]: Proceedings of the conference. Ed. by V. A. Antonets, S. B. Parin and V. G. Yakhno. Nizhniy Novgorod, IPF RAN. 234 p. Pp. 22-26. (In Russ.).

Aleksandrova, N. Sh. (2020) Bilingvizm i drugie proyavlenia funktsionirovania yazykovoi sistemy v svete plastichnosti mozga [Bilingualism and other manifestations of the functioning of the language system in light of brain plasticity]. Philological sciences. Scientific essays of higher education, no. 6-2, pp. 170-176. (In Russ.). DOI: https://www.doi. org/10.20339/PhS.6-20.170

Anayban, Z. V. (2011) Mezhetnicheskaia situatsia i etnopoliticheskie protsessy v postsovetskoi Tuve [Interethnic situation and political processes in post-Soviet Tuva]. In: Issledovaniya po prikladnoy $i$ neotlozhnoy etnologii [Studies in applied and urgent ethnology]. Moscow, IEA RAN. Vol. 227. 25 p. (In Russ.).

Aref'ev, A. L., Bakhtikireeva, U. M. and Sinyachkin, V. P. (2021) Problemy bilingvizma v sisteme shkol'nogo yazykovogo obrazovaniya Respubliki Tyva [Bilingualism in language education in secondary schools of the Republic of Tuva]. New Research of Tuva. no. 1, pp. 255-272. DOI: https://www.doi.org/10.25178/nit.2021.1.14

Akhutina, T.V. (2014) Svyaz' semanticheskoi slozhnosti, vremeni priobretenia i chastotnosti slova [The relations between semantic complexity, age of acquisition and word frequency]. In: Neyrolingvisticheskiy analiz leksiki, semantiki $i$ pragmatiki [A neurolinguistic analysis of vocabulary, semantics and pragmatics]. Moscow, Yazyki slavyanskoy kul'tury. $424 \mathrm{p}$. Pp. 186-189. (In Russ.).

Balonov, L. Ya., Deglin, V. L. and Chernigovskaia T. V. (2004) Funktsional'naia asimmetriya mozga v organizatsii rechevoi deyatel'nosti [Functional brain asymmetry and its role in organizing verbal activity]. In: Khrestomatiya po neyropsikhologii [An Anthology on Neuropsychology] / ed. by E. D. Khomskaya. Moscow, Institute of General Humanitarian Research; Moscow Psychological and Social Institute. 896 p. Pp. 527-541. (In Russ.).

Vizel', T. G. (2002) Neyrolingvisticheskii analiz atipichnykh form afazii (sistemnyi integrativnyi podkhod) [Neurolinguistic analysis of atypical forms of aphasia: a systemic and integrative approach]: Abstract of Diss.... Doctor of Psychology. Moscow. 49 p. (In Russ.).

Vizel', T. G. (2009) K voprosu o prirode afazii [On the nature of aphasia]. Defectology, no. 6, pp. 65-70. (In Russ.).

Vlasova, R. (2016) Normativnaya baza risunkov «Predmet i deystvie» [A normative set of “object-action” pictures]. Russian journal of cognitive science, vol. 3 (1-2), pp. 34-54. (In Russ.).

Ivanov, V. Vs. (2004) Lingvistika tret'ego tysyacheletia: Voprosy $k$ budushchemu [Linguistics of the third millennium: some questions to the future]. Moscow, Yazyki slavyanskoy kul'tury. 208 p. (In Russ.).

Katunin, D. A. (2009) Yazykovoe zakonodatel'stvo v respublikakh Sibiri [Linguistic legislation in the republics of Siberia]. Language and Culture, no. 4 (8), pp. 13-24. (In Russ.). 
Lyashevskaya, O. N. and Sharov, S. A. (2009) Chastotnyy slovar' sovremennogo russkogo yazyka (na materialakh Natsional'nogo korpusa russkogo yazyka) [A frequency dictionary of contemporary Russia from the materials of the Russian National Corpus]. Moscow, Azbukovnik. 1112 p. (In Russ.).

Sereedar, N. Ch. (2018) Tuvinskiy yazyk kak sredstvo obshcheniya tuvintsev: problemy i perspektivy [Tuvan language as a means of communication among Tuvans: problems and prospects]. New Research of Tuva, no. 1, pp. 4-19 (In Russ.). DOI: https://www.doi.org/10.25178/nit.2018.1.1

Chernigovskaia, T. V. (2017) Lateralizatsiia iazykov u bilingva [Languages lateralization in bilinguals]. In: Chernigovskaia T. V. Cheshirskaia ulybka kota Shredingera : iazyk i soznanie [The Cheshire Smile of Schroedinger's Cat: Language and Consciousness]. Moscow, Izdatel'skii Dom IaSK; Iazyki slavianskoi kul'tury. 448 p. Pp. 251-261. (In Russ.).

Tsvetkova, L. S. (1988) Afaziya i vosstanovitel'noe obuchenie [Aphasia and speech therapy]. Moscow, Prosveshchenie. 207 p. (In Russ.).

Tsybenova, Ch. S. (2013) Assotsiativnyy eksperiment v kontekste issledovaniya yazykovoy situatsii: na primere Respubliki Tyva [Associative experiment in the study of a language situation: the case of the Republic of Tuva]. Voprosy psikholingvistiki, vol. 17, pp. 180-193. (In Russ.).

Akinina, Y., Malyutina, S., Ivanova, M., Iskra, E., Mannova, E. and Dragoy, O. (2015) Russian normative data for 375 action pictures and verbs. Behavior Research Methods, vol. 47 (3), pp. 691-707.

Bialystok, E. (2009) Bilingualism: The good, the bad, and the indifferent. Bilingualism: Language and Cognition, vol. 12(1), pp. 3-11. DOI: https://doi.org/10.1017/S1366728908003477

García-Pentón, L., Pérez Fernández, A., Iturria-Medina, Y., Gillon-Dowens, M., Carreiras, M. (2014) Anatomical connectivity changes in the bilingual brain. NeuroImage, vol. 84, pp. 495-504. DOI: https://doi.org/10.1016/j. neuroimage.2013.08.064

Goral, M., Lerman, A. (2020) Variables and Mechanisms Affecting Response to Language Treatment in Multilingual People with Aphasia. Behavioral Sciences, vol. 10, pp. 144-157. DOI: https://doi.org/10.3390/bs10090144

Kałamała, P., Drozd'zowicz, A., Szewczyk, J., Marzecov'a, A., Wodniecka, Z. (2018) Task strategy may contribute to performance differences between monolinguals and bilinguals in cognitive control tasks: ERP evidence. Journal of Neurolinguistics, vol. 46, pp. 78-92. DOI: https://doi.org/10.1017/S1366728913000564

Lorenzen, B. and Murray, L. (2008) Bilingual Aphasia: A Theoretical and Clinical Review. American Journal of SpeechLanguage Pathology, vol. 17, pp. 299-317. DOI: https://doi.org/10.1044/1058-0360(2008/026)

Mechelli, J. T. Crinion, U. Noppeney, J. O’Doherty, J. Ashburner, R. S. Frackowiak, et al. (2004) Structural plasticity in the bilingual brain: Proficiency in a second language and age at acquisition affect grey-matter density. Nature, vol. 431 (7010), p. 757. DOI: https://doi.org/10.1038/431757a

Morrison, C.M., Ellis, A.W. and Quinlan, P.T. (1992) Age of acquisition, not word frequency affects object naming, not object naming, not object recognition. Memory \& Cognition, vol.20, p. 705-714. DOI: https://doi.org/10.3758/BF03202720

Paetzold, G. and Specia, L. (2016) Inferring Psycholinguistic Properties of Words. Proceedings of NAACL-HLT 2016, San Diego, California, June 12-17, pp. 435-440. DOI: https://doi.org/10.18653/v1/N16-1050

Submission date: 11.04.2021. 